\title{
Um Olhar Evolucionista para os Mecanismos Cognitivos Associados às Trocas Sociais
}

\author{
Tiago José Benedito Eugênio ${ }^{1}$ \\ Universidade Federal do Rio Grande do Norte
}

\begin{abstract}
RESUMO - A psicologia evolucionista propõe uma investigação sobre as origens e os propósitos das habilidades cognitivas que constituem a cognição social humana. Este artigo procura apresentar a teoria do contrato social como um modelo evolucionista para o estudo de mecanismos cognitivos associados às trocas sociais e da cooperação, tais como: detecção de trapaça, memória de faces, senso de justiça, influência da informação e conhecimento prévio, vigilância e teoria da mente que regulam, fundamentalmente, nossas interações sociais. Conclui-se que um olhar evolucionista para a mente humana gera hipóteses, enquanto a teoria dos jogos fornece métodos para testá-las, nos auxiliando a compreender a natureza humana.
\end{abstract}

Palavras-chave: teoria do contrato social, teoria dos jogos, cooperação, psicologia evolucionista, trocas sociais

\section{An Evolutionary View of Cognitive Mechanisms Associated with Social Exchange}

\begin{abstract}
Evolutionary psychology proposes the investigation of the origins and purposes of cognitive skills that constitute human social cognition. This article presents the social contract theory as an evolutionary model for the study of the cognitive mechanisms and cooperation, such as cheating detection, memory for faces, sense of justice, the influence of prior knowledge and information, vigilance and theory of mind that regulate social interactions. It is concluded that an evolutionary view of human mind produces hypotheses, while game theory provides methods to test them, helping us to understand human nature.
\end{abstract}

Keywords: social contract theory, game theory, cooperation, evolutionary psychology, social exchanges

Seres humanos são seres essencialmente sociais. É mínima a chance de um bebê humano sobreviver caso ele não receba atenção e cuidado de seus coespecíficos (Hyde, 2005; Poindron, 2005). Estudos na área de desenvolvimento mostram que os infantes primatas nascem com uma série de características físicas e comportamentais que os predispõe à interação social e à formação de vínculos afetivos com os seus cuidadores (Fantz, 1963; Hrdy, 2001). Da mesma forma, é quase nula a chance de um ser humano adulto sobreviver sem qualquer contato com outro indivíduo da sua espécie. As interações sociais, por sua vez, são mediadas por um repertório amplo de funções cognitivas, tais como memória, raciocínio e linguagem (Cosmides \& Tooby, 1992; Pinker, 2004).

Consideremos uma situação específica, na qual o indivíduo coloca em prática esse repertório cognitivo: a escolha de sujeitos para compor um grupo de trabalho escolar. Trabalhando em equipe, os estudantes exercitam uma série de habilidades. Ao mesmo tempo em que estudam o conteúdo das disciplinas, eles aprendem a avaliar os colegas. Por exemplo, caso um aluno não coopere na realização das atividades coletivas, é bem provável que a memória dos indivíduos do grupo seja ativada e favoreça o ostracismo do aluno que não cooperou do próximo trabalho. Essa decisão pode ser tomada porque os integrantes do grupo apresentam habilidades cognitivas inerentes à mente humana e específicas para: identificar e reconhecer o indivíduo; relembrar

1 Endereço para correspondência: UFRN - Campus Universitário, Centro de Biociências, Departamento de Fisiologia, Caixa Postal 1511, Lagoa Nova, RN. CEP 59078-970. E-mail: tiagoeugenio20@gmail.com dos diversos aspectos históricos de interações que ocorreram entre o aluno não cooperador com o grupo; e avaliar que não é justo um aluno receber um benefício por um trabalho que não lhe custou nada, dentre outras.

Até meados do século XX, as escolas tradicionais da psicologia postulavam que esse repertório cognitivo era aprendido com a experiência. Durante o tempo de supremacia do behaviorismo, de 1913 a cerca de 1960, todo comportamento era concebido como aprendido e capaz de ser modificado através do r-eforço skinneriano, por exemplo. Em contraposição, nessa época, surgiram também trabalhos a respeito da precedência das influências genéticas e das tendências herdadas sobre as respostas condicionadas (Pinker, 2004). A afirmação behaviorista de que todo o comportamento é aprendido foi contestada pelo trabalho de treinamento animal dos Brelands, dois ex-alunos de Skinner. Marian e Keller Breland (1961) treinaram animais para apresentações em circos oferecendo comida para os animais como reforço. Assim, "utilizando-se a comida como reforço, o porco e o guaxinim rapidamente se condicionavam a apanhar uma moeda, carregá-la por uma certa distância e colocá-la em um banco de brinquedo" (Schultz \& Schultz, 2007, p. 303). Mas durante as apresentações, foi observado que os animais treinados demonstravam uma propensão à "transferência instintiva". Em algumas situações, os animais simplesmente revertiam ao comportamento inato que tinha precedência sobre o comportamento aprendido, mesmo que essa reversão atrapalhasse na obtenção do alimento. Nesse caso, o reforço não era tão eficaz quanto afirmavam os behavioristas (Schultz $\&$ Schultz, 2007). 
Na segunda metade do século XX, organizam-se esforços para convergir saberes de diversas áreas, como a psicologia cognitiva, as ciências da computação e a linguística, os quais implicam na origem de um novo paradigma para o estudo do comportamento humano. Durante a revolução cognitiva, retoma-se o conceito de consciência, considerada como parcialmente biológica e social, e postula-se um modelo de mente humana similar a um computador, provida de componentes responsáveis pela entrada e saída da informação - como uma unidade de memória que armazena o programa e os dados recebidos, e um processador com capacidade de manipular e transformar símbolos. A metáfora do computador aplicada à mente humana permitiu perceber também que, a exemplo do computador, ela deve ser também programada para desempenhar suas diversas tarefas (Penna, 1986; Schultz $\&$ Schultz, 2007). No entanto, o seu sucesso não foi maior porque seus modelos computacionais omitiam as origens e o objetivo da capacidade humana de processar informações. Dessa forma, o olhar investigativo era voltado, ainda, para o papel do ambiente, das relações familiares e da cultura como construtores da mente humana, negligenciando a sua história evolutiva. "A psicologia evolucionista encontrou a peça faltante no quebra-cabeça ao fornecer uma vasta especificação dos tipos de questões que envolvem o processamento de informações destinados à mente humana solucionar - problemas de sobrevivência e de reprodução" (Buss, 1999, p. 30).

A lógica da biologia evolutiva começou a informar a psicologia sobre as origens e as raízes da cultura e da ordem social, considerando o seu suporte biológico. Em termos gerais, este artigo procura sintetizar e discutir o repertório cognitivo regulador das trocas sociais com base nos pressupostos da psicologia evolucionista. A revisão apresenta a Teoria do Contrato Social como um modelo evolucionista adequado para o estudo de diferentes habilidades cognitivas humanas e, por conseguinte, contribui para elucidar mecanismos cognitivos, tais como: detecção de trapaça, memória de faces, senso de justiça, influência da informação e conhecimento prévio, vigilância e teoria da mente que regulam, fundamentalmente, nossas interações sociais.

\section{Perspectiva Evolucionista}

Interpretações modernas sobre a evolução das trocas sociais e da cooperação têm se centrado no estudo comparativo com outras espécies e na evolução de estratégias, sobretudo reprodutivas, dos indivíduos, as quais dependem do tamanho, estruturação dos grupos e dos padrões de interação entre os membros do grupo (Clutton-Brock, 1991, 2009). Essa perspectiva vislumbra a organização social como um subproduto da evolução das estratégias individuais engendradas por um longo processo histórico-evolutivo.

O cerne dessa perspectiva encontra-se nas ideias de Charles Darwin sobre a evolução das espécies. Para Darwin (1859/1996), o ambiente seleciona os indivíduos que detêm características que trazem mais benefícios do que custos - concedendo-lhes mais chances de sobrevivência e de reprodução - e isso implica uma seleção natural, a qual é responsável pela modificação das espécies ao longo do tempo e do espaço. A seleção natural é, dessa forma, o processo através do qual variantes favorecidas em uma população sobrevivem e se reproduzem mais. Nesse processo, o ambiente seleciona os indivíduos, passando esse conjunto de traços para as gerações seguintes (Cronin, 1995; Meyer \& El-Hani, 2005).

Nesse sentido, é proposta uma conexão direta entre gerações. Assim sendo, segundo as ideias de Darwin, todos os organismos da Terra têm ancestrais comuns que podem ser mais primitivos ou mais recentes. Essa é uma hipótese poderosa para predizermos que a história de vida das espécies é caracterizada por uma continuidade e que comportamentos de natureza cognitiva, emocional e moral variam em grau e não em tipo, estando presente em outras espécies, além da humana (Bekoff, 2004). Essa é uma predição largamente corroborada, na medida em que observamos que atos de cooperação tais como a partilha de comida, proteção do grupo, traição e a manipulação do outro para benefício próprio podem ser encontrados em outros animais como os morcegos vampiros (Denault \& MacFarlane, 1995), peixes (Taborsky, 1985) e aves (Koenig, 1981).

\section{Relações Sociais Como um Jogo}

Há várias décadas, os fundadores da teoria dos jogos, John Von Neumann e Oskar Morgenstern (1944) estabeleceram uma distinção fundamental entre jogos de "soma zero" e "soma não-zero". Como exemplo para os primeiros, citamos o tênis, o xadrez e a sinuca, nos quais a vitória de um competidor é a derrota do outro. Em jogos de soma não-zero, o fato de um jogador ganhar não necessariamente é algo ruim para o(s) outro(s). Em jogos de soma não-zero, os interesses dos jogadores sobrepõem-se. A aplicação desses conceitos da Economia e da Matemática à Biologia foi de suma importância para o estudo empírico do comportamento social, sobretudo da cooperação em humanos. Em 1972, John Maynard Smith, biólogo evolucionista inglês, introduziu a ideia de estratégias que se perpetuam no tempo por serem imunes a estratégias alternativas, ou seja, estratégias evolutivamente estáveis (EEE ou ESS, sigla de evolutionarily stable strategy), inaugurando-se, na biologia, uma teoria de jogos evolucionários. Por conferir maior probabilidade de sobrevivência e reprodução, essas estratégias são, em geral, selecionadas naturalmente e são encontradas em uma frequência maior na população (Cronin, 1995).

Diversos são os jogos usados para estudar o comportamento humano e as diferentes estratégias utilizadas pelos jogadores, entre eles: dilema do prisioneiro, jogo do ditador, do ultimato, tragédia dos comuns e bens públicos (Alencar \& Yamamoto, 2009). No dilema do prisioneiro conta-se uma história hipotética sobre dois prisioneiros que serão interrogados separadamente. Cada prisioneiro tem uma escolha: ficar quieto ou então acusar o companheiro. Os policiais oferecem uma diminuição da pena pela delação do comparsa a cada um deles, de forma independente. Se um dos prisioneiros trair o companheiro, acusando-o e o outro permanecer em silêncio, o que traiu ganha o direito de liberdade enquanto o comparsa silencioso cumpre uma pena de 10 anos. Se ambos permanecerem em silêncio, um cooperar com o outro, os policiais só podem condená-los 
por dois anos cada um. Por outro lado, se ambos delatarem o outro cada um cumpre uma pena de oito anos.

Axelrod e Hamilton (1981) testaram diversas estratégias desenvolvidas por diversos cientistas e organizaram torneios virtuais, simulando diferentes estratégias para o dilema do prisioneiro com interações repetidas. Os pesquisadores verificaram que as estratégias mais cooperativas eram as que mostravam melhores resultados. Dentre elas, a estratégia olho-por-olho foi a que trouxe mais vantagem para os jogadores. Nessa estratégia, o jogador segue duas regras: sempre coopera na primeira interação (não acusa o parceiro nem confessa o crime) e depois faz exatamente o que o seu parceiro fez na jogada anterior; trapaceia se tiver sido trapaceado e coopera caso tenha obtido cooperação.

Desde então, começou-se a analisar como a cooperação, paradoxalmente, poderia emergir mesmo entre sujeitos egoístas, primordialmente interessados em satisfazer seus desejos mais imediatos, pois como mostra o dilema dos prisioneiros, a escolha individual não implica necessariamente no resultado mais favorável para ambos. Assim, por meio da teoria dos jogos, procurou-se compreender, por exemplo, quais são as condições necessárias para haver cooperação e em quais circunstâncias compensa cooperar.

\section{A mente como um produto evolutivo}

Se aceitarmos os pressupostos da teoria da evolução e tivermos como verdade que nossos membros, dentes e olhos são produtos da seleção natural, por que não admitir que a nossa mente também seja um produto do processo evolutivo? Ademais, se entendemos a organização social e, por consequência as sociedades, como um produto do intrincado jogo de estratégias individuais, devemos, portanto, investigar como a mente do indivíduo funciona, quais são suas funções e partes. Logo, é imprescindível investigar por que a mente foi moldada do modo como é e ainda como se deu esse processo.

Segundo Laland e Brown (2002) existem pelo menos cinco abordagens que procuram, sob o ponto de vista evolutivo, soluções para essa investigação: a sociobiologia, a ecologia comportamental humana, a psicologia evolucionista, a memética e a coevolução gene-cultura. Dentre elas, a psicologia evolucionista se destaca na medida em que se propõe a investigar o funcionamento da mente e também como os estímulos ambientais (inputs) interagem com a mente (hardware) para produzir o comportamento observável (outputs). Nesse sentido, a perspectiva evolucionista amplia o estudo do comportamento humano para além da análise física, de suas causas próximas - mecanismos fisiológicos; e passa a considerar e investigar também os mecanismos psicológicos evoluídos. Para tanto, se debruça sobre o seu surgimento na história da vida, adotando o método comparativo com outras espécies, entre indivíduos e entre os sexos (Buss, 1999) e procura compreender a sua função ou o valor para a sobrevivência e reprodução do indivíduo.

Dentro da psicologia evolucionista não existe ainda um consenso definido sobre a anatomia e fisiologia da mente. Para alguns, reza a hipótese de que nosso cérebro funcionaria através de estruturas físicas modulares de domínios específicos, os quais teriam evoluído em resposta às pressões específicas do ambiente e, portanto, orientados à solução de problemas também específicos enfrentados cotidianamente pelos nossos ancestrais como caçar animais, coletar vegetais, fugir de predadores, interagir com amigos, lidar com agressores, encontrar, e selecionar parceiros reprodutivos e criar os filhos (Buss, 1999; Cosmides \& Tooby, 1992). A teoria da modularidade recebe suporte empírico, como, por exemplo, as evidências de crianças e adultos cujas habilidades gerais são excepcionamente pobres e, no entanto, demonstram habilidades altamente sofisticadas em domínios especializados. Além disso, os processos neurais responsáveis pela capacidade linguística parecem estar centrados em áreas específicas do cérebro: as áreas de Broca e de Wernicke. Traumatismos na área de Broca parecem afetar o uso da gramática especialmente, enquanto os que ocorrem na área de Wernicke influenciam a compreensão (Pinker, 2002).

No entanto, questionam outros que nesse modelo de alta especialização, sem espaço para um processamento central, não haveria fluidez cognitiva, isto é, uma comunicação e flexibilidade no seu funcionamento frente às experiências internas e externas ao indivíduo (Chiappe \& MacDonald, 2005). Por outro lado, o arqueólogo Steven Mithen (2002), com base em registro fóssil, defende a presença e função adaptativa de um processador geral na mente. Para ele, o caminho da evolução da mente da nossa espécie apresenta, tanto a direção de um aumento da fluidez cognitiva e o desenvolvimento de formas generalizadas de pensamento, quanto de especialização ou modularização.

A psicologia evolucionista propõe que as condições ambientais atuais são bastante diferentes das condições nas quais a nossa espécie evoluiu e que existe um descompasso temporal entre o que somos (ambiente atual) e aquilo que Bowlby (2002) chamou de Ambiente de Adaptação Evolutiva, no qual populações ancestrais sobreviveram e se reproduziram.

\section{Teoria do Contrato Social}

O arranjo entre os pressupostos da perspectiva econômica e evolucionista no que tange à organização social permitiu que Cosmides e Tooby (1992) postulassem a Teoria do Contrato Social, a qual procura explicar a evolução dos mecanismos reguladores das trocas sociais e da cooperação na espécie humana. Para tanto, eles levantaram a hipótese da existência de adaptações cognitivas específicas para regular as trocas sociais, entre elas: capacidade de identificar e reconhecer diferentes indivíduos; relembrar diversos aspectos históricos de interações com os indivíduos; detectar possíveis sujeitos violadores das regras sociais na população; expressar e compreender os desejos e as necessidades dos outros; e representar os custos e benefícios nas trocas sociais dos mais diversos itens (Buss, 1999; Cosmides \& Tooby, 1992).

Para testar suas hipóteses, Cosmides e Tooby (1992) aplicaram em estudantes universitários a tarefa de seleção de Wason. Esse teste consiste na apresentação de quatro cartões mostrando, por exemplo, os caracteres "A", "B", "3" e "4"; é explicado que cada carta possui, em uma face, uma letra e, na outra, um número, e a hipótese em questão é: "se uma carta tem uma vogal de um lado, tem um número par do 


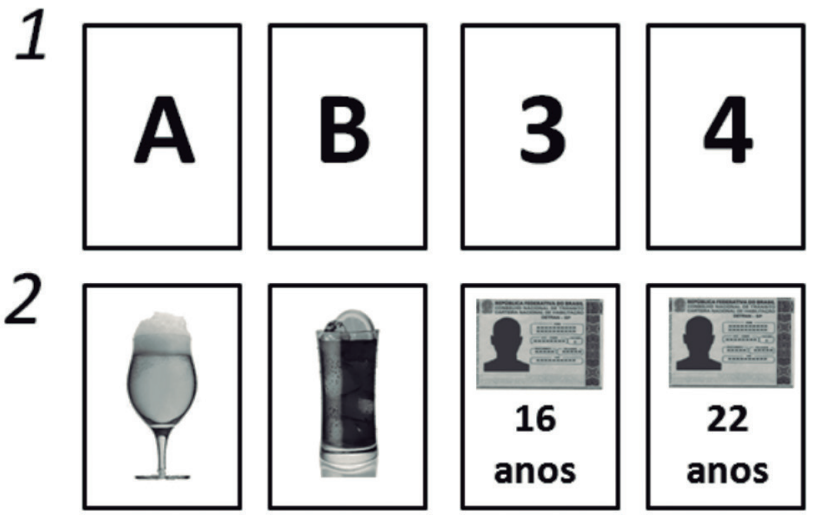

Figura 1. Exemplos de configurações de teste com a Tarefa de Seleção de Wason.

outro." Nesse caso, o participante deveria dizer quais cartas ele deveria virar, no mínimo, para confirmar a hipótese.

As primeiras constatações de Cosmides e Tooby (1992) foram de que em relações que envolviam o raciocínio lógico e abstrato, menos de $25 \%$ dos estudantes acertavam na escolha dos cartões, no exemplo, "A" e "3" (Figura 1.1). Entretanto, o desempenho dos estudantes mudava quando a hipótese condicional se referia a uma regra social não abstrata. Era solicitado aos estudantes se imaginarem como um barman, o qual deveria cumprir uma lei que proíbe a venda de bebidas alcoólicas para menores de 20 anos. Dessa forma, as cartas representavam os fregueses: "bebendo cerveja", "bebendo refrigerante" (que equivaleriam às letras " $A$ " $\mathrm{e}$ "B", respectivamente), com "16 anos" e com "22 anos" que equivaleriam às " 3 " e "4", respectivamente (Figura. 1.2). Nessa versão não abstrata, mais de $75 \%$ dos estudantes respondiam corretamente o teste, escolhendo virar as cartas "bebendo cerveja" e "16 anos".

Nesse sentido, Cosmides e Tooby (1992) propuseram que os diferentes problemas - formalmente semelhantes estariam sendo processados por estruturas neurais distintas, por módulos de domínios específicos, especializados na detecção de violadores de regras sociais. Comunidades primitivas da América também foram analisadas, como os Shiwiar da Amazônia equatoriana. Sugiyama, Tooby e Cosmides (2001) investigaram a presença de adaptações cognitivas para trocas sociais dessa sociedade aplicando um teste de seleção de Wason adaptado para populações iletradas. O desempenho dos Shiwiar não foi diferente dos graduandos de Harvard - uma evidência de que existem aspectos que são universais na espécie humana, que independem da cultura. Entretanto, os mecanismos psicológicos não são imutáveis e imunes aos fatores culturais. Por exemplo, Dehaene, Izard, Spelke e Pica (2008), ao estudar um grupo indígena na Amazônia, os Mundurucus, que apresenta um léxico numérico reduzido e pouca ou nenhuma educação formal, e estudantes norte-americanos, observaram que a concepção de escala numérica logarítmica era uma intuição presente nos dois grupos estudados. Os Mundurucus, em todas as situações usavam a escala logarítmica. Os estudantes norte-americanos utilizavam a escala linear em uma contagem pequena, mas quando submetidos a uma situação de contagem maior, utilizavam a escala logarítmica. Os resultados desse estudo apontam que a escala linear de contagem é uma herança cultural, que não se desenvolve na ausência da educação formal.

\section{Detecção de Trapaça}

No ambiente ancestral da espécie humana, episódios litigiosos deveriam ter existido apenas quando houvesse extrema escassez de recursos. A organização social deveria ter sido igualitária, sem privilégios para alguns membros nem ocorrência de trapaceiros, visto que o tamanho reduzido do grupo proporcionaria uma fiscalização mais rigorosa do comportamento de cada um (Broom, 2006). A fiscalização deveria ter sido importante para coibir os trapaceiros: aqueles indivíduos que usufruem do benefício, mas não pagam o custo devido pelo mesmo (Trivers, 1971). Com o tempo, entretanto, os grupos cresceram e, por consequência, a identificação dos trapaceiros se tornou uma tarefa mais difícil.

Alencar, Siqueira e Yamamoto (2008) estudaram o comportamento moral de crianças por meio do jogo dos bens públicos, no qual a criança recebia três chocolates e decidia quantos ela doaria para um fundo comum. A cada chocolate doado eram acrescentados mais dois no bem comum e, no final do jogo, este era dividido igualmente entre todos os indivíduos. As crianças foram separadas em grupos pequenos e grandes. Nos grupos menores, a generosidade foi maior, pois os indivíduos monitoravam o comportamento dos colegas. Entretanto, nos grupos maiores, em que não é fácil perceber quem doa, a cooperação caiu rapidamente, mostrando que o egoísmo prevalece quando o indivíduo não percebe um ambiente propício para a cooperação.

Fehr e Gachter (2002) realizaram um jogo no qual os indivíduos podiam investir em um bem comum e decidir quanto investiam. Além disso, podiam punir os outros em três unidades monetárias, mas pagavam uma unidade, ou seja, havia um custo para a punição. Foram comparados dois grupos: um com possibilidade de punição e outro sem punição. Os resultados desse estudo apontam que a cooperação declina se não houver punição e que a existência dela é tão importante quanto a sua ameaça.

Nesse sentido, os indivíduos que reconheciam e puniam os trapaceiros diminuíam suas chances de receber o ônus da relação com um trapaceiro e, provavelmente, obtinham maiores chances de sobrevivência e reprodução (Broom, 2006). Cosmides e Tooby (1992) propuseram que o processo evolutivo tratou de resolver o problema específico do risco de trapaça, equipando os indivíduos com funções cognitivas para detectar possíveis trapaceiros.

\section{Memória de Faces}

Mealey, Daood e Krage (1996) trataram de investigar a predisposição para detectar trapaceiros e seus resultados sugeriram que essa função cognitiva também influenciava a recordação de faces. Em um experimento utilizando fotografias, Mealey et al. (1996) forneceram evidências de que os humanos seriam equipados com um módulo específico para detectar trapaceiros. Em uma simulação de uma partida singular do 
jogo dilema do prisioneiro, os participantes se lembraram das fotografias dos jogadores que não cooperavam (Oda, 1997).

Entretanto, existem trabalhos que não dão suporte à hipótese de memória diferencial para trapaceiros (Barclay \& Lalumière, 2006; Kiyonari, Tanida, \& Yamagishi, 2000). Outros sugerem uma maior facilidade na detecção de sujeitos cooperadores (Brown, Palameta, \& Moore, 2003). E, outros ainda, postulam a existência de memórias diferenciais tanto para detectar trapaceiros como para detectar cooperadores (Brown \& Moore, 2000).

Dado que as populações podem diferir quanto à prevalência de indivíduos não confiáveis, Barclay (2008) levantou a hipótese de que a proporção de indivíduos cooperadores e trapaceiros na população poderia afetar a lembrança dos mesmos. Essa hipótese foi testada através de um jogo de confiança informatizado, no qual eram vistas 40 fotos de rostos masculinos de cooperadores e indivíduos que não cooperavam no jogo em diferentes proporções $(20 / 80,50 / 50$ ou 80/20). Seus resultados apontaram que os trapaceiros são lembrados com maior frequência quando são mais raros; o mesmo ocorre com a lembrança dos cooperadores. Com isso, sugere que a memória de faces simplesmente é um subproduto de um mecanismo geral de lembrança de eventos raros e não um mecanismo psicológico evoluído. Existe uma falta de consenso na literatura sobre a existência ou não de uma memória diferencial para detectar trapaça. Entretanto, na atualidade, é um consenso que a sua coibição é fundamental para a consolidação e manutenção das trocas sociais (Trivers, 1971).

\section{Senso de Justiça}

No jogo do ultimato, dois jogadores devem dividir uma quantia limitada de recurso. Um deles, o proponente, é o que fará uma oferta ao outro, o receptor. Os jogadores são informados que participarão apenas uma vez e que não é possível barganhar, ou seja, uma vez feita a oferta pelo proponente, cabe ao receptor dizer se a aceita ou não. Caso o receptor aceite a oferta, o recurso é dividido de acordo com a proposta deferida. Entretanto, se o receptor a rejeita, ambos os jogadores não recebem nada. A solução racional é o proponente oferecer o menor valor possível e o receptor aceitá-lo. Afinal, receber um valor, mesmo que seja baixo, é melhor do que receber nada. Entretanto, os resultados das pesquisas apontam que os seres humanos não jogam de forma absolutamente racional este jogo. A maioria dos proponentes faz uma oferta justa (até $80 \%$ deles oferecem de $40 \%$ a $50 \%$ do total) e mais da metade dos receptores rejeitam ofertas menores que 30\% do valor total (Page, Nowak, \& Sigmund, 2000; Roth, Prasnikar, Okuno-Fujiwara, \& Zamir, 1991).

Mas quando desenvolvemos um senso de justiça? Hamlin, Wynn e Bloom (2007) sugerem que os seres humanos têm um sentido moral desde o "início da vida". Para mostrar isso, os pesquisadores apresentaram um teatro de fantoches para bebês, no qual havia uma personagem que ajudava outro e outras cenas em que outro personagem não cooperava. Depois do teatro, eram apresentados os personagens para as crianças e foi observado que as mesmas tinham uma tendência a preferir os personagens que cooperavam em cena.
Brosnan e De Wall (2003) indicaram, mediante um experimento elegante, como os macacos prego, Cebus apella, dispõem de um sentimento agudo de justiça. Os pesquisadores ensinaram esses pequenos primatas a intercambiar fichas por comida, mas notaram que os macacos se negaram a fazê-lo, caso a quantidade de alimento fosse menor do que a quantidade fornecida para outro macaco, cujo intercâmbio era por ele contemplado e avaliado. Chimpanzés respondem de forma semelhante, rejeitando a desigualdade. Entretanto, mostram grandes diferenças entre os grupos de acordo com o grau de parentesco e tamanho do grupo, como nos humanos (Brosnan, Schiff, \& De Waal, 2005).

Esses estudos apontam que o senso de justiça não é uma idiossincrasia da espécie humana. É importante lembrar que, em geral, esse senso de justiça é utilizado de forma "intuitiva", não requerendo necessariamente um esforço cognitivo consciente para pô-lo em prática. Dito de outra forma, é uma característica própria e arraigada da espécie, que nos permite reagir de uma determinada maneira frente aos possíveis problemas durante uma relação e situação de trocas sociais.

\section{Informação e Conhecimento Prévio}

No jogo do ditador, assim como no jogo do ultimato, dois jogadores devem dividir uma quantia limitada de recurso. $\mathrm{O}$ ditador, proponente do recurso, é quem faz uma oferta que é recebida obrigatoriamente pelo receptor, sem qualquer contestação. Servátka (2009) estudou como as informações sobre o receptor modulam o comportamento do ditador. Os resultados apontam que a generosidade do ditador é maior quando este adquire informações sobre o receptor. Da mesma forma, Eckel e Grossman (1996) mostram que os ditadores tendem a fazer maiores doações quando lhes são passadas informações de que o receptor é membro, por exemplo, de uma instituição filantrópica.

Outro fator que pode aumentar a generosidade também é o fato do proponente conhecer previamente o receptor. Nowak, Page e Sigmund (2000) estudaram os efeitos do conhecimento prévio, por parte do proponente, quanto aos valores que o receptor teria aceitado em participações anteriores no jogo do ultimato. Os pesquisadores mostram que o custo de se rejeitar uma oferta relativamente baixa é contrabalanceado pela "reputação" de ser um indivíduo que somente aceita ofertas mais justas. Isso faz com que o receptor receba ofertas maiores em jogadas posteriores. Logo, concluem os pesquisadores, a reputação favorece a justiça nas divisões do recurso.

\section{Vigilância}

Experiências em grupos na vida real (Ellikson, 1991) confirmam a existência de mecanismos, como a fofoca, para fiscalizar o cumprimento das normas do grupo e, por consequência, coibir a violação de uma regra social. A fofoca, nesse sentido, é um mecanismo importante de vigilância que parece aumentar a generosidade em humanos (Dunbar, 1999). Em experimentos realizados com computadores, indivíduos tiveram que dividir um recurso com outro seguindo às regras 
a

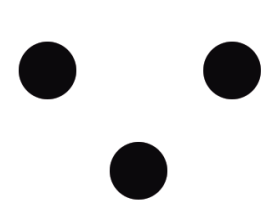

$b$

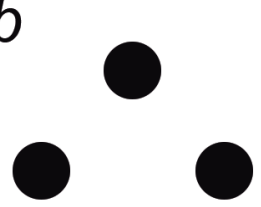

Figura 2. a. Pontos dispostos como uma face (condição de vigilância). b. Pontos rotacionados $180^{\circ}$, (condição neutra). Adaptado de Rigdon et al., (2009)

do jogo do ditador. Em um grupo, os ditadores tomavam a decisão em um desktop cujo papel de parede estampava olhos estilizados voltados para o mesmo e, em outro, os ditadores decidiam em um desktop com uma imagem sem olhos. Foi verificado que os ditadores eram mais generosos quando tomavam a decisão no computador com os olhos estampados (Haley \& Fessler, 2005; Mifune, Hashimoto, \& Yamagishi, 2010).

Contudo, pistas mais sutis de vigilância parecem também influenciar o comportamento dos indivíduos. Rigdon, Ishii, Watabe e Kitayama (2009) entregaram para o ditador, no momento da sua tomada de decisão, um cartão com três pontos - dispostos como uma face (Figura 2a). Em outra condição, os ditadores viam o mesmo estímulo, no entanto, rotacionado $180^{\circ}$ (Figura 2b). Observou-se que os participantes ditadores alocaram mais recurso para os receptores quando eram submetidos à condição de vigilância. Os pontos distribuídos como se fosse uma face parecem ativar a área fusiforme do cérebro - responsável pelo reconhecimento de faces - sendo, portanto, suficiente para modificar o comportamento social dos ditadores (Bednar \& Miikkulainen, 2003).

\section{Teoria da Mente}

A capacidade de expressar e compreender os desejos e as necessidades dos outros é outra adaptação cognitiva específica para regular as trocas sociais. Premack e Woodruff(1978) estudaram o comportamento de chimpanzés que, assim como os humanos, pensam em seus coespecíficos. Assim, cunharam a expressão "Teoria da Mente" que significa a capacidade para imputar estados mentais aos outros e a si próprio. Nesse sentido, ela é essencial tanto para a autorreflexão, quanto para a coordenação da ação social.

Com humanos, é empregado o clássico experimento "Problema da Sally-Anne" (Frith \& Frith, 1999), no qual é exibida uma cena para os sujeitos. Primeiramente, Sally entra, guarda uma bola em um local, por exemplo, atrás do sofá e sai da cena. Entra em cena a Anne, que retira a bola de trás do sofá, coloca-a em outro local, por exemplo, dentro de uma caixa, e sai. Sally retorna em busca da bola - nesse ponto a cena é interrompida. Em seguida, pergunta-se para o sujeito: “onde Sally irá procurar pela bola?".

Os pesquisadores observaram que, até 3 anos de idade, as crianças apresentam dificuldades de entender que diferentes pessoas podem ter representações distintas de uma mesma realidade. Nesse caso, essas crianças respondem, em geral, que Sally irá procurar a bola dentro da caixa. Todavia, quando a mesma pergunta era feita para crianças com mais de 6 anos, quase todas as crianças respondiam corretamente, que Sally iria procurar no local onde tinha deixado a bola, isto é, atrás do sofá. No que se refere à idade crítica para o desenvolvimento da "Teoria da Mente", há divergências entre os pesquisadores (Ottoni, Rodriguez, \& Barreto, 2006).

No entanto, é inegável que com tal recurso cognitivo, o ser humano pode, por exemplo, planejar estratégias e tomar decisões críticas numa situação social. Além disso, tornou-se possível ao Homo sapiens prever que ideias os outros estariam formando a seu respeito, bem como tornou mais sofisticadas as relações e a comunicação intra e intergrupo, habilitando-o a entender artifícios da expressão humana como a ironia, a dissimulação, o sofrimento, o interesse e a falsidade.

\section{Considerações Finais}

O estudo da cognição humana não é uma novidade. $\mathrm{Na}$ verdade, há mais de três décadas os cientistas investigam, de diferentes formas, o repertório cognitivo da mente humana. A psicologia evolucionista, no entanto, é uma novidade na medida em que propõe uma investigação sobre as origens e os propósitos das habilidades cognitivas que constituem a cognição social humana. Para uma teoria evolucionista da mente, mais do que delimitar e descrever funções cognitivas, mostra-se necessário explicar a razão de ser das mesmas, considerando as pressões seletivas que as moldaram ao longo do tempo evolutivo. Nesse sentido, seres humanos não são vislumbrados como tábulas rasas (Pinker, 2004), mas produtos de um processo evolutivo. A perspectiva evolucionista propõe que viemos ao mundo equipados com predisposições para aprender a cooperar, a distinguir o justo e virtuoso do traiçoeiro, a ser leal e prezar pela lealdade, a conquistar boa reputação diante dos nossos semelhantes, intercambiar produtos e informações, a dividir o trabalho e a modelar sua individualidade e seus vínculos sociais a partir das reações do outro.

O que se procurou mostrar é que um olhar evolucionista para a mente humana e seus mecanismos cognitivos gera hipóteses e predições testáveis que nos auxiliam a compreender de forma mais precisa a natureza do Homo sapiens e de outros animais sociais. Enquanto espécie, somos providos de uma natureza universal, mas essa universalidade existe primariamente no nível de mecanismos psicológicos evoluídos, não de comportamentos expressos, e a cultura, certamente, desempenha um papel preponderante nessa expressão. Em consonância com esses pressupostos, não faz sentido opor os efeitos culturais a implicações de base genética sobre a constituição do comportamento humano, uma vez que sem a cultura não há manifestação de determinadas tendências biológicas.

O crescimento da psicologia evolucionista ocorreu na medida em que essa área do conhecimento cooptou diferentes saberes até então não relacionados. $\mathrm{O}$ arranjo entre a perspectiva evolucionista e a aplicação da teoria dos jogos na biologia e na psicologia possibilitou a elaboração de estudos robustos sobre os mecanismos psicológicos que teriam evoluído e sido responsáveis pela regulação das trocas sociais e da coope- 
ração na espécie humana. Mais do que investigar as origens e os propósitos desses mecanismos, a teoria evolucionista e o uso metodológico da teoria dos jogos demonstraram a plasticidade dos mecanismos psicológicos responsáveis pela adaptação do sujeito aos diferentes contextos.

Possivelmente o maior desafio atual da abordagem evolucionista é compreender com mais precisão justamente a plasticidade dos mecanismos psicológicos. Certamente, tomamos decisões levando em conta uma miríade de fatores tais como o tamanho do grupo, sexo e idade dos indivíduos com quem iremos cooperar, e informações que temos sobre eles e ainda se confiamos ou não em quem estamos ajudando. De acordo com esse entendimento, futuras investigações são necessárias para avaliar, sobretudo, o efeito do contexto na expressão do comportamento humano. Ao estudar as variáveis e a dinâmica da escolha entre cooperar ou desertar pode-se pensar, por exemplo, em ambientes e contextos mais sofisticados para coibir a trapaça e garantir as melhores circunstâncias que fomentam a cooperação, harmonia, civilidade e zelo pelo bem comum.

Nesse sentido, o estudo do contexto pode servir como um modelo eficaz de prudência e uma ferramenta para estudar não apenas a origem e a evolução das normas de convivência de um grupo social, mas também para modelar ambientes de trocas sociais mais contextualizados, ecológicos e próprios de cada comunidade. Afinal, nossas mentes foram engendradas por mecanismos psicológicos que evoluíram por seleção natural para favorecer comportamentos adaptativos, entre os quais se encontra o interesse remoto pelo bem-estar dos demais e as predisposições típicas de uma espécie social e cooperadora.

\section{Referências}

Alencar, A. I., Siqueira, J. O., \& Yamamoto, M. E. (2008). Does group size matter? Cheating and cooperation in Brazilian school children. Evolution and Human Behavior, 29, 42-48.

Alencar, A. I., \& Yamamoto, M. E. (2009). A teoria dos jogos como metodologia de investigação científica para a cooperação na perspectiva da psicologia evolucionista. Psico, PUCRS, 39, 522-529.

Axelrod, R., \& Hamilton, W. D. (1981). The evolution of cooperation. Science, 21, 1390-1396.

Barclay, P., \& Lalumière, L. M. (2006). Do people differentially remember cheaters? Human Nature, 17, 98-113.

Barclay, P. (2008). Enhanced recognition of defectors depends on their rarity. Cognition, 107, 817-828.

Bednar, J., \& Miikkulainen, R. (2003). Learning innate face preferences. Neural Computation, 15(7), 1525-1557.

Bekoff, M. (2004). Why justice and fair play: Cooperation, forgiveness, and morality in animals. Biology and Philosophy, 19, 489-520.

Bowlby, L. (2002). Apego: A natureza do vínculo. Vol 1 da trilogia: Apego e Perda. São Paulo: Editora Martins Fontes.

Breland, K., \& Breland, M. (1961). The misbehavior of organisms. American Psychologist, 16, 681-684.

Broom, D. M. (2006). The evolution of morality. Applied Animal Behavioral Science, 100, 20-28.

Brosnan, S., \& De Waal, F. B. M. (2003). Monkeys reject unequal pay. Nature, 425, 297-299.
Brosnan, S. F., Schiff, H. C., \& De Waal, F.B. M. (2005). Tolerance for inequity may increase with social closeness in chimpanzees. Proceedings of the Royal Society of London, Series B 1560, 253-258.

Brown, W., \& Moore, C. (2000). Is prospective altruist-detection an evolved solution to the adaptive problem of subtle cheating in cooperative ventures? Supportive evidence using the Wason selection task. Evolution and Human Behavior, 21, 25-37.

Brown, W. M., Palameta, B., \& Moore, C. (2003). Are there nonverbal cues to commitment? An exploratory study using the zero-acquaintance video presentation paradigm. Evolutionary Psychology, 1, 42-69.

Buss, D. M. (1999). Evolutionary psychology: The new science of the mind. Boston: Allyn and Bacon.

Chiappe, D., \& MacDonald, K. (2005). The evolution of domaingeneral mechanism in intelligence and learning. The Journal of General Psychology, 132, 5-40.

Clutton-Brock, T. H. (1991). The evolution of parental care. New Jersey: Princeton University Press.

Clutton-Brock T. H. (2009). Structure and function in mammalian societies. Philosophical Transaction of the Royal Society Biological Sciences, 364, 3229-3242.

Cosmides, L., \& Tooby, J. (1992). Cognitive adaptations for social exchange. In H. J. Barkow, L. Cosmides \& J. Tooby (Eds.), The adapted mind: Evolutionary psychology and the generation of culture (pp. 163-228). New York: Oxford University Press.

Cronin, H. (1995). A formiga e o pavão: Altruísmo e seleção sexual de Darwin até hoje. Campinas: Papirus.

Darwin, C. (1996). The origin of species. Oxford: Oxford University Press. (Trabalho Original Publicado em 1859)

Dehaene, S., Izard, V., Spelke, E., \& Pica, P. (2008). Log or linear? Distinct intuitions of the number scale in Western and Amazonian indigene cultures. Science, 30, 1217-1220.

Denault, L. K., \& McFarlane, D. A. (1995). Reciprocal altruism between male vampire bats, Desmodus rotundus. Animal Behaviour, 49, 855-856.

Dunbar, R. I. M. (1999). Culture honesty and the free-rider problem. In: R. I. M. Dunbar, C. D. Night, \& C. Power (Orgs.). The evolution of culture (pp. 194-213). Edinburgh: Edinburgh University Press.

Eckel, C. C., \& Grossman, J. P. (1996). Altruism in anonymous dictator games. Games and Economic Behavior, 16, 181-191.

Ellickson, R. C. (1991). Order without law: How neighbors settle disputes. Cambridge: Harvard University Press.

Fantz, R. (1963). Pattern vision in newborn infants. Science, 140(3564), 296-297.

Fehr, E., \& Gachter, S. (2002). Altruistic punishment in humans. Nature: $415,137-140$.

Frith, C. D., \& Frith, U. (1999). Interacting minds: A biological basis. Science, 256, 1692-1695.

Haley, K. J., \& Fessler, D. M. T. (2005). Nobody's watching? Subtle cues affect generosity in an anonymous economic game. Evolution and Human Behavior, 26, 245-256.

Hamlin, J. K., Wynn, K., \& Bloom, P. (2007). Social evaluation by preverbal infants. Nature, 450, 557-559.

Hrdy, S. B. (2001). Mãe natureza: Uma visão feminina da evolução: Maternidade, filhos e seleção natural. Rio de Janeiro: Campus.

Hyde, J. S. (2005). The gender similarities hypothesis. American Psychologist, 6, 581-592. 
Kiyonari, T., Tanida, S., \& Yamagishi, T. (2000). Social exchange and reciprocity: Confusion or a heuristic? Evolution and Human Behavior, 21, 411-427.

Koenig, W. D. (1981). Space competition in the acorn woodpecker: Power struggles in a cooperative breeder. Animal Behaviour, 29, 396-409.

Laland, K. N., \& Brown, G. (2002). Sense and nonsense: Evolutionary perspectives on human behaviour. Oxford: Oxford University Press.

Mealey, L., Daood, C., \& Krage, M. (1996). Enhanced memory for faces of cheaters. Ethology and Sociobiology, 17, 119-128.

Meyer, D., \& El-Hani, C. N. (2005). Evolução: O sentido da biologia. São Paulo: Editora Unesp.

Mifune, N., Hashimoto, H., \& Yamagishi, T. (2010). Altruism toward in-group members as a reputation mechanism. Evolution and Human Behavior, 31, 109-117.

Mithen, S. (1996/2002). A pré-história da mente: Uma busca das origens da arte, da religião e da ciência. São Paulo: Editora Unesp.

Nowak, M. A., Page, K. M., \& Sigmund, K. (2000). Fairness versus reason in the ultimatum game. Science 289, 1773-1775.

Oda, R. (1997). Biased face recognition in the prisoner's dilemma game. Evolution and Human Behavior, 29, 35-41.

Ottoni, E. B., Rodriguez, C. F., \& Barreto, J. C. (2006). Teoria da Mente e compreensão da representação gráfica de conteúdos mentais ("balões de pensamento"). Interação em Psicologia, $10,225-234$.

Page, K. M., Nowak, M. A., \& Sigmund, K. (2000). The spatial ultimatum game. Proceedings of the Royal Society of London $B, 267,2177-2182$.

Penna, A. G. (1986). Cognitivismo, consciência e comportamento político. São Paulo: Vértice.

Pinker, S. (2002). O Instinto da linguagem: Como a mente cria a linguagem. São Paulo: Martins Fontes.

Pinker, S. (2004). Tábula rasa: A negação contemporânea da natureza humana. São Paulo: Companhia das Letras.
Poindron, P. (2005). Mechanisms of activation of maternal behaviour in mammals. Reproduction Nutrition Development, 45, 341-351.

Premack, D., \& Woodruff, G. (1978). Does the chimpanzee have a theory of mind? Behavioral and Brains Science, 1, 515-526.

Rigdon, M., Ishii, K., Watabe, M., \& Kitayama, S. (2009). Minimal social cues in the dictator game. Journal of Economic Psychology, 30, 358-367.

Roth, A., Prasnikar, V., Okuno-Fujiwara, M., \& Zamir, S. (1991). Bargaining and market behavior in Jerusalem, Ljubljana, Pittsburgh, and Tokyo: Some experimental evidence. American Economic Review, 81, 1068-1095.

Schultz, D. P., \& Schultz, S. E. (2007). História da psicologia moderna. São Paulo: Thomson.

Servátka, M. (2009). Separating reputation, social influence, and identification effects in a dictator game. European Economic Rewiew, 53, 197-209.

Sugiyama, L. S., Tooby, J., \& Cosmides, L. (2001). Cross-cultural evidence of cognitive adaptations for social exchange among the Shiwiar of Ecuadorian Amazonia. PNAS, 99, 11537-11542.

Taborsky, M. (1985). Breeder-helper conflict in a cichlid fish with brood care helpers: An experimental analysis. Behaviour, 95, 45-57.

Trivers, R. (1971). The evolution of reciprocal altruism. Quarterly Review of Biology, 46, 35-57.

Von Neumann, J., \& Morgenstern, O. (1944). Theory of game and economic behavior. Princeton: Princeton University Press.

Recebido em 09.12.2010

Primeira decisão editorial em 29.10.2012

Versão final em 17.11.2012

Aceito em 17.11.2012 